\title{
COMPOSIÇÃO DE VOLÁTEIS E PERFIL DE AROMA \\ E SABOR DE MÉIS DE EUCALIPTO E LARANJA ${ }^{1}$
}

\author{
Deborah Helena Markowicz BASTOS ${ }^{2}$, Maria Regina Bueno FRANCO $^{3, *}$, \\ Maria Aparecida Azevedo Pereira DA SILVA ${ }^{3}$, Natália Soares JANZANTTI³ ${ }^{3}$ Márcia O. M. MARQUES ${ }^{4}$
}

\section{RESUMO}

Neste trabalho foram analisados os compostos voláteis de amostras de mel de eucalipto e laranja colhidos nos estados de São Paulo e de Minas Gerais. O isolamento dos voláteis foi realizado empregando-se uma técnica de "headspace" dinâmico, a separação efetuada por cromatografia gasosa de alta resolução e a identificação por espectrometria de massas, Îndices de Kovats e padrões, quando disponíveis. Foram identificados no mel de laranja o benzaldeído, o óxido cis de linalol, n-heptanal, 6-metil-5-hepten-2-ona, octanal e fenilacetaldeído, e em mel de eucalipto, o nonanal, 2-heptanona, 2-heptanol, octanol e nonanol. A caracterização sensorial desses méis foi obtida por Análise Descritiva Quantitativa e a aplicação de Análise dos Componentes Principais aos dados revelou que os descritores "queimado" e "sabor residual" caracterizam o mel de eucalipto, enquanto "floral" e "cera" caracterizam o mel de laranja. Entre os compostos identificados, o nonanal e o nonanol apresentaram contribuição sensorial importante ao mel de eucalipto, enquanto o fenilacetaldeído e o benzaldeído foram relacionados com os principais descritores do mel de laranja.

Palavras-chave: compostos voláteis; sabor e aroma; avaliação sensorial; mel.

\section{SUMMARY}

VOLATILE COMPOSITION AND AROMA AND FLAVOR PROFILES OF EUCALYPTUS AND ORANGE HONEYS. Volatile compounds of orange and eucalyptus bee honeys from the states of São Paulo and Minas Gerais were isolated by a dynamic headspace technique and separated by high resolution gas chromatography. Volatile compounds were identified by gc-mass spectrometry and the Kovats Indices. Benzaldehyde, cis-linalool oxide, n-heptanal, 6 methyl-5-hepten-2-ona, octanal and phenylacetaldeyde were detected in orange honey. Nonanal, 2-heptanone, 2-heptanol, octanol and nonanol were identified in eucalyptus samples. Quantitative Descriptive Analysis and Principal Component Analysis revealed that orange honey can be sensorially characterized by "waxy" and "floral" descriptors, while eucalyptus honey by a "burnt" and "after-taste". Phenylacetaldeyde and benzaldehyde were related to these important descriptors in characterizing orange honey, as determined by sniffing, while nonanal and nonanol were found to be important contributors to the eucalyptus honey aroma.

Keywords: volatile compounds; flavor; sensory evaluation; honey.

\section{1 - INTRODUÇÃO}

Méis provenientes de diferentes origens botânicas possuem aromas e sabores diferentes, de modo que pessoas treinadas podem identificar méis provenientes de uma determinada fonte, pelo seu aroma e sabor. $\mathrm{O}$ aroma pode ser descrito como extremamente suave e agradável, ou ainda, como no mel de tabaco, ser descrito como muito desagradável.

Existem dezenas de variedades de mel de abelhas que podem ser diferenciadas pela flora, pelo lugar ou época de colheita, ou ainda, segundo as técnicas de preparação. O mel de origem floral pode proceder do néctar das flores de uma única espécie vegetal (méis monoflorais) ou de várias (méis poliflorais). Rigorosamente, não existe mel monofloral, contudo, uma pequena quantidade de néctar de outras plantas melíferas não influi marcadamente no sabor e cor de um mel onde predomine o néctar de uma única espécie de flores.

Métodos outros que não a análise polínica de méis, que permitam a identificação da origem botânica de méis monoflorais, têm sido objeto de diversos estudos. Ênfase é dada à procura de "marcadores químicos", ou seja, substâncias presentes no mel capazes de definir a sua florada de origem $[10,14,17,18,19,22,27,30]$. O estudo dos compostos voláteis presentes em méis monoflorais é um tema que tem despertado muito interesse, notadamente nestas pesquisas que visam definir "marcadores químicos" para méis monoflorais $[6,7,8$, $11]$.

O aroma e o sabor característico são conferidos aos alimentos pela presença dos compostos voláteis. Em geral, os compostos voláteis mais agradáveis do mel são aqueles com menor ponto de ebulição. O aroma e o sabor estão no seu ponto ótimo quando o mel é retirado diretamente da colméia, pois podem ser modificados pelo processamento usado para extraí-lo dos favos. O "envelhecimento" do mel leva a uma perda de seu aroma característico, devido ao aparecimento de compostos como álcoois superiores, quando ocorre contaminação microbiológica, e de compostos furânicos, relacionados à degradação de açúcares presentes no mel [9, 19]. Assim, a utilização de compostos voláteis, presentes em méis como "marcadores químicos", deve observar a presença de variáveis como tempo de armazenamento, processamento e presença de microrganismos, notadamente leveduras.

Outro fator importante refere-se à metodologia empregada no isolamento dos compostos voláteis. O sistema de destilação-extração simultâneo de NickersonLikens, que emprega calor, tem sido uma das técnicas

\footnotetext{
${ }^{1}$ Recebido para publicação em 12/01/01. Aceito para publicação em 21/12/01.

${ }^{2}$ Universidade São Francisco - Av. São Francisco de Assis, 218 CEP 12900-OOO Bragança Paulista, São Paulo, Brasil

${ }^{3}$ UNICAMP - Faculdade de Engenharia de Alimentos, Departamento de Ciência de Alimentos. Caixa Postal 6121. CEP 13083-970. Cidade Universitária Zeferino Vaz, Campinas, SP, Brasil

${ }^{4}$ Instituto Agronômico - Centro de Genética, Biologia Molecular e Fitoquímica, Caixa Postal 28.CEP 13001-970, Campinas, SP, Brasil

* A quem a correspondência deve ser enviada.
} 
mais empregada pelos pesquisadores. No entanto, o aquecimento durante esta etapa leva à formação de compostos furânicos. Em função da metodologia empregada, pode ocorrer ainda a discriminação de alguns compostos em função de sua volatilidade e peso molecular.

As pesquisas sobre compostos voláteis de mel têm dado pouca importância à correlação entre a análise química (instrumental) e a análise sensorial. No entanto, a correlação da análise sensorial com a instrumental tem ganho credibilidade e espaço nos últimos anos, pois permite classificar produtos de acordo com algum critério e permite prever a qualidade sensorial a partir de medidas [26]. Alguns trabalhos visando a avaliação qualitativa dos efluentes cromatográficos já foram relatados em meados da década de 60 [1, 2]. Para verificar a contribuição odorífera de compostos voláteis presentes em mel, alguns pesquisadores empregaram esta técnica (“sniffing”) na última década [8, 17, 18].

Este trabalho teve como objetivos: verificar as diferenças químicas entre os compostos voláteis presentes em 2 tipos de méis uniflorais (eucalipto e laranja) recém-colhidos, provenientes dos Estados de São Paulo e Minas Gerais, e estabelecer as diferenças de aroma e sabor segundo a origem floral.

\section{2 - MATERIAL E MÉTODOS}

\section{1 - Material}

Para a caracterização dos produtos recém-colhidos, amostras de mel de eucalipto e laranja foram adquiridas em favos diretamente de apicultores dos Estados de São Paulo e de Minas Gerais logo após a colheita. Foram analisados três lotes de mel de eucalipto (dois lotes colhidos em julho de 1995 e um lote em junho de 1996) e dois lotes de mel de laranja (colhidos em outubro de 1995). Para cada lote, cerca de $10 \mathrm{Kg}$ do produto foram extraídos dos favos, tomando-se $300 g$ para cada análise química, que foi feita em duplicata. Para a análise sensorial foram analisados 3 lotes de $5 \mathrm{Kg}$ de méis (2 de eucalipto e 1 de laranja), que não haviam sofrido qualquer espécie de tratamento térmico. Uma amostra de mel de eucalipto e uma de mel de laranja foram adquiridas diretamente do apicultor, em 1994, e a outra amostra de mel de eucalipto foi adquirida em um entreposto comercial, de origem idônea.

\section{2 - Métodos}

\subsection{1 - Isolamento dos compostos voláteis}

Empregou-se uma técnica de "headspace" dinâmico [15], para tanto, $300 \mathrm{~g}$ de mel foram diluídos em $200 \mathrm{~mL}$ de água destilada e submetidos à captura por sucção dos compostos voláteis em polímero poroso (Porapak Q) por um período de 3 horas. Posteriormente, os voláteis capturados na armadilha foram eluídos com $300 \mu \mathrm{L}$ de acetona (Carlo Erba, grau cromatográfico), conforme descrito por BASTOS, DA SILVA \& FRANCO [4].

\subsection{2 - Separação dos compostos voláteis por cromatografia gasosa de alta resolução}

Os compostos voláteis, presentes nos isolados como uma mistura complexa, foram separados por cromatografia gasosa de alta resolução, utilizando-se um cromatógrafo Varian modelo 3300, equipado com uma coluna capilar de $50 \mathrm{~m}$ de comprimento e $0,2 \mathrm{~mm}$ de diâmetro interno, com fase líquida (SE-54) e espessura do filme igual a $0,25 \mu \mathrm{m}$.

Para o mel de eucalipto, a temperatura inicial da coluna foi mantida a $50^{\circ} \mathrm{C}$ por 8 minutos, e depois com programação de $1^{\circ} \mathrm{C} / \mathrm{min}$ elevou-se a temperatura até $75^{\circ} \mathrm{C}$, e com gradiente de $2^{\circ} \mathrm{C} / \mathrm{min}$ até $110^{\circ} \mathrm{C}$. A temperatura final foi de $200^{\circ} \mathrm{C}$, obtida com um gradiente de $5^{\circ} \mathrm{C} / \mathrm{min}$. A quantidade de amostra injetada foi de $2 \mu \mathrm{L}$.

Para a separação dos compostos voláteis de mel de laranja, a temperatura inicial da coluna foi mantida a $50^{\circ} \mathrm{C}$ por 8 minutos. Com gradiente de temperatura de $2^{\circ} \mathrm{C} / \mathrm{min}$., elevou-se a temperatura a $75^{\circ} \mathrm{C}$ e depois a $150^{\circ} \mathrm{C}$ com um gradiente de $5^{\circ} \mathrm{C} / \mathrm{min}$. A temperatura final foi de $200^{\circ} \mathrm{C}$, com programação de $6^{\circ} \mathrm{C} / \mathrm{min}$. A quantidade de amostra injetada foi de $1 \mu \mathrm{L}$.

O injetor empregado foi o do tipo split/splitless,no modo splitless e a uma temperatura de $230^{\circ} \mathrm{C}$. A temperatura do detetor de ionização de chama foi de $250^{\circ} \mathrm{C}$ e a velocidade linear do gás de arraste, hidrogênio, foi de $45 \mathrm{~cm} / \mathrm{s}$.

Os dados sobre tempos de retenção e as porcentagens relativas dos compostos voláteis foram obtidos através de um integrador Varian, modelo 4290, acoplado ao cromatógrafo. A quantificação foi feita por normalização.

\subsection{3 - Identificação dos compostos voláteis de mel de eucalipto e laranja}

\section{Espectrometria de massas}

Os compostos voláteis de mel foram analisados em um cromatógrafo gasoso Shimadzu GC17A acoplado a um espectrômetro de massas QP 5000, do tipo quadrupolo. Empregou-se uma coluna de 30m de comprimento e $0,25 \mathrm{~mm}$ de diâmetro interno, com $0,25 \mu \mathrm{m}$ de espessura do filme de fase ligada, DB-1. A programação da coluna foi a mesma que no item 2.2.2.

- Parâmetros empregados:

- Gás de arraste: Hélio

- Temperatura da interface: $230^{\circ} \mathrm{C}$

- Temperatura do injetor: $230^{\circ} \mathrm{C}$

- Voltagem de ionização: $70 \mathrm{eV}$

Índices de Kovats

Uma mistura de padrões de alcanos, de C8-C18 em acetona, foi adicionada a cada isolado contendo os compostos voláteis de mel. Os dados de retenção foram então aplicados à conhecida equação para o cálculo dos Índices de Kovats [29]. 


\section{Assinalamento das estruturas}

Os espectros de massas obtidos para os compostos voláteis foram comparados com a biblioteca de dados e os índices de Kovats obtidos experimentalmente confrontados com os descritos na literatura, confirmando a ordem de eluição na fase estacionária utilizada [6]. Com a confirmação da identidade obtida por cromatografia gasosa-espectrometria de massas, indice de Kovats e disponibilidade de padrão, o composto foi considerado positivamente identificado.

\subsection{4 - Comparação da porcentagem relativa dos compostos voláteis}

A comparação das porcentagens relativas dos compostos voláteis das amostras recém-colhidas, foi efetuada através de análise de variância (ANOVA), utilizandose "lotes" como fonte de variação.

\subsection{5 - Análise sensorial}

\section{Análise Descritiva Buantitativa}

O perfil de cada amostra (duas de mel de eucalipto e uma de mel de laranja) foi desenvolvido pelo método de Análise Descritiva Quantitativa (ADQ) conforme metodologia proposta por STONE et al. [28].

Inicialmente, indivíduos foram recrutados e selecionados com base no poder discriminativo, reprodutibilidade de cada indivíduo e consenso com a equipe sensorial com relação ao sabor de mel. O levantamento da terminologia descritiva das amostras de mel foi realizado através do método de rede [24]. Os oito provadores selecionados foram solicitados a avaliar o aroma e sabor das amostras de méis uniflorais descrevendo suas similaridades e diferenças. Desta forma, a equipe gerou de forma consensual, uma ficha descritiva das amostras, bem como definições e referências para cada descritor gerado, de acordo com os procedimentos recomendados por STONE et al. [28] e MEILGARD, CIVILLE \& CARR [23].

Para avaliação do aroma, $30 \mathrm{~g}$ de cada amostra foi servida em xícara de fundo negro, coberta com vidro de relógio e codificada com número de três dígitos. Para a avaliação do sabor, $10 \mathrm{~g}$ de cada amostra foi servida em copos descartáveis de $50 \mathrm{~mL}$, também com código de três dígitos. Ambas as avaliações foram realizadas em cabines individuais, sob luz vermelha, para mascarar qualquer variação com relação à aparência das amostras.

Uma amostra de mel de laranja e duas de eucalipto foram avaliadas pela equipe sensorial descritiva, em três repetições, utilizando-se a ficha de avaliação descritiva previamente desenvolvida pela equipe sensorial, onde constava ao lado de cada descritor, uma escala não estruturada de 9cm, ancorada nos termos "fraco" e "forte". As amostras foram servidas monadicamente e avaliadas utilizando-se delineamento experimental de blocos completos casualizados.

Os dados foram submetidos à análise de variância (ANOVA) com fontes de variação (provador, amostra, provador x amostra), teste de Tukey, Análise de Componentes Principais (ACP), utilizando-se do programa SAS
(SAS Use's Guide: Basics Version 5 Edition 1985, Institute Inc, n. C. USA).

\section{CG-olfatometria ("Sniffing")}

A contribuição sensorial de cada composto volátil para o perfil sensorial das amostras foi determinada utilizando-se a técnica de "sniffing". Para tanto, o efluente da coluna cromatográfica foi dividido de forma que uma parte seguiu para o detector de ionização de chama (FID), e outra foi conduzida por um tubo de sílica desativada até o nariz do provador, que descreveu qualitativamente o aroma percebido, simultaneamente ao registro da corrida cromatográfica pelo integrador. Esta análise foi realizada por 6 provadores treinados, que avaliaram as amostras em duplicata.

\subsection{6 - Análise polínica}

A análise polínica foi efetuada pelo Laboratório de Abelhas, do Departamento de Ecologia Geral da Universidade de São Paulo. Utilizou-se análise microscópica de grão de pólen, presentes nas amostras de mel, após acetólise [3, 20].

\section{3 - RESULTADOS E DISCUSSÃo}

\section{1 - Porcentagem relativa e identificação dos com- postos voláteis de mel de eucalipto e laranja}

A análise polínica confirmou a origem botânica das amostras de mel como sendo mesmo de eucalipto e de laranja.

Foram detectados 21 compostos voláteis no mel de eucalipto por cromatografia gasosa de alta resolução e embora não tenha sido possível verificar as diferenças estatísticas na composição de voláteis entre os 3 lotes (pois foram provenientes de diferentes anos, devido à seca que inviabilizou a colheita em São Paulo), foi obtido um cromatograma típico dos compostos voláteis de méis de eucalipto. No mel de laranja foram detectados 21 compostos voláteis e a ANOVA também revelou que não houve diferença significativa $(\mathrm{p} \leq 0,05)$ entre os perfis de voláteis das amostras recém-colhidas de méis de laranja nos dois lotes do mesmo ano. Os perfis cromatográficos típicos dos compostos voláteis dos méis de eucalipto e dos méis de laranja estão representados nas Figuras 1 e 2.

As Tabelas 1 e 2 (mostrando apenas os compostos voláteis detectados acima de níveis de traços em todas as análises, com exceção de 4 compostos identificados e outros 3 não identificados, porém sensorialmente importantes) apresentam as percentagens relativas dos compostos voláteis das amostras de mel de eucalipto e laranja, respectivamente. Foram incluídos nestas tabelas os íons principais obtidos por espectrometria de massas, além dos índices de Kovats, para demonstrar que os compostos voláteis não identificados, diferiram nos dois tipos de méis.

O mel de eucalipto apresentou como compostos majoritários o nonanal e 4 compostos não identificados. O mel de laranja apresentou como compostos majoritá- 
rios o fenilacetaldeído, o 2-isononenal e dois compostos não identificados. O composto com o Índice de Kovats de 864 foi encontrado em proporções significativamente diferentes $(\mathrm{p} \leq 0,05)$ entre os lotes analisados.

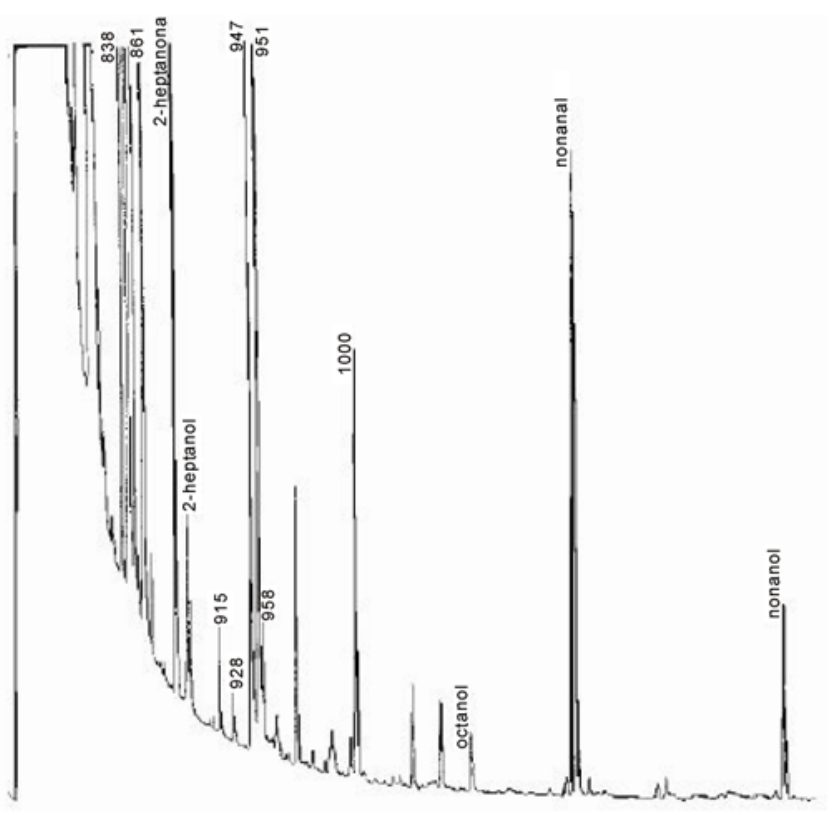

FIGURA 1. Perfil cromatográfico do mel de eucalipto.

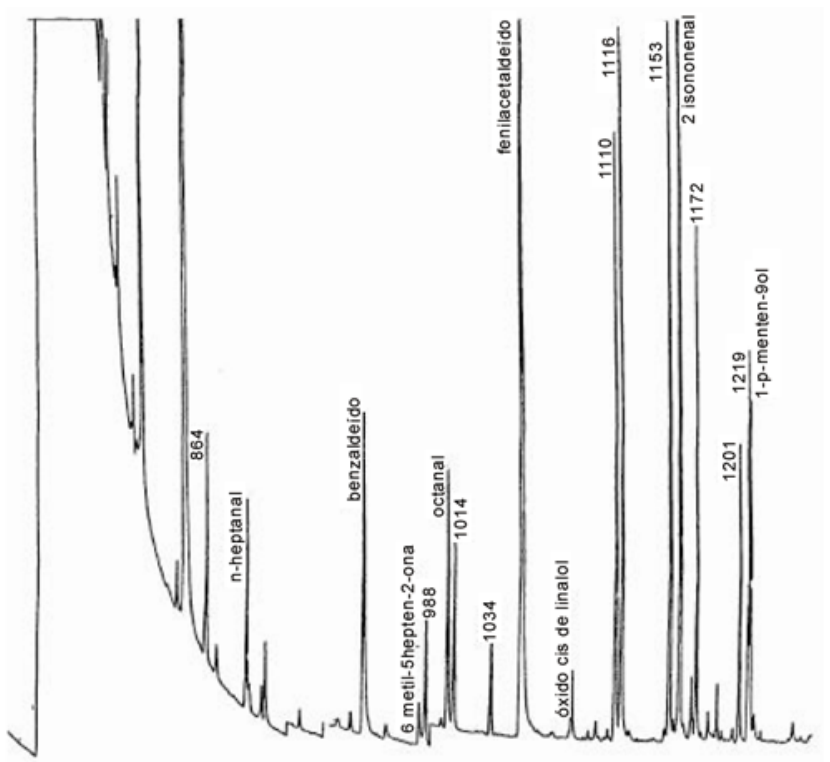

FIGURA 2. Perfil cromatográfico do mel de laranja.

A presença de 2-heptanona em mel foi relatada anteriormente em mel de nabo silvestre [7] e a presença de nonanal foi relatada em cera de abelhas por FERBER \& NURSTEN [12]. A presença de 2-heptanol foi relatada por MAGA [21] e o n-heptanal foi identificado em mel de eucalipto e laranja por BOUSETA, COLLINS \& DUFOUR [7] e em mel de tupelo por OVERTON \&
MANURA [25]. O benzaldeído foi relatado em vários tipos de mel $[6,7,18,21,25,30]$, enquanto o fenilacetaldeído foi identificado por VISSER, ALLEN, SHAW [30] em mel de "manuka" (Leptospernum Scoparum); por OVERTON \& MANURA [25] em mel de laranja; por BICCHI, BELLIARDO \& FRATTINI [6] em méis poliflorais do Piemonte; por GUYOT, SCHEIRMAN \& COLLIN [18] em mel de Calluna vulgaris e Erica arborea. O óxido cis de linalol foi relatado em vários méis [6, 21, 25, 30], enquanto o 1-p-menten-9-al foi encontrado em mel de “manuka” por VISSER, ALLEN, SHAW [30].

TABELA 1. Porcentagem relativa (média) dos compostos voláteis das amostras de mel de eucalipto.

\begin{tabular}{|c|c|c|c|}
\hline Composto & $\begin{array}{c}\text { Índices } \\
\text { de Kovats }\end{array}$ & Média $^{1} \pm d . p .^{2}$ & Íons majoritários $\mathrm{m} / \mathrm{z}$ (abundância relativa) \\
\hline NI & 838 & $23,9 \pm 1,6$ & nd \\
\hline NI & 864 & $5,9 \pm 1,1$ & $43(100), 60(63), 41(57), 58(29), 45(29), 42(26), 56(16))$ \\
\hline NI & 864 & $12,1 \pm 2,8$ & $43(100), 45(33), 41(32), 83(30), 42(26), 56(22), 59(21)$ \\
\hline 2-heptanona & 892 & $\operatorname{tr} \pm n d$ & $43(100), 58(42), 40(19), 41(13), 51(5), 42(5), 71(5), 114(1)$ \\
\hline NI & 892 & $0,7-\operatorname{tr} \pm$ nd & $45(100), 55(48), 42(43), 43(36), 41(31), 70(30), 40(25)$ \\
\hline 2-heptanol & 900 & $1,1 \pm 0,3$ & $45(100), 43(27), 41(26), 55(18), 44(17), 42(9), 56(6)$ \\
\hline NI & 900 & $0,8 \pm 0,2$ & nd \\
\hline NI & 915 & $0,6-\operatorname{tr} \pm n d$ & nd \\
\hline NI & 928 & $0,3 \pm 0,2$ & nd \\
\hline NI & 947 & $7,5 \pm 0,4$ & $45(100), 57(69), 41(61), 43(60), 85(23), 42(14), 44(10)$ \\
\hline NI & 951 & $25,3 \pm 2,9$ & $45(100), 43(95), 41(93), 69(55), 57(29), 44(19), 87(14)$ \\
\hline NI & 958 & $2,1-\operatorname{tr} \pm n d$ & nd \\
\hline NI & 1000 & $3,6 \pm 1,3$ & $85(100), 41(87), 43(76), 57(29), 40(26), 67(26), 55(26)$ \\
\hline 2-octanol & 1018 & $1,8-\operatorname{tr} \pm n d$ & $45(100), 43(38), 41(27), 44(26), 55(16), 69(7), 58(7)$ \\
\hline nonanal & 1128 & $11,2 \pm 2,6$ & $41(100), 43(81), 44(52), 57(52), 56(33), 55(33), 42(28)$ \\
\hline nonanol & 1211 & $2,7 \pm 0,6$ & $41(100), 40(95), 43(76), 56(52), 55(48), 42(48), 70(29)$ \\
\hline
\end{tabular}

${ }^{1}$ Média ou amplitude de 6 determinações (3 lotes em duplicata); ${ }^{2}$ d.p.: desvio padrão; NI: composto não identificado; $t r$ = traços; nd= não determinado

TABELA 2. Porcentagem relativa (média) dos compostos voláteis das amostras de mel de laranja.

\begin{tabular}{|c|c|c|c|}
\hline Composto & $\begin{array}{c}\text { Índice de } \\
\text { Kovats }\end{array}$ & Média ${ }^{1} \pm$ d.p. ${ }^{2}$ & Íons majoritários $\mathbf{m} / \mathbf{z}$ (abundância relativa) \\
\hline NI & 864 & $3,7 \pm 3,5$ & nd \\
\hline n-heptanal & nd & $5,1 \pm 0,7$ & $43(100), 44(82), 41(81), 42(53), 40(49), 70(27), 55(26)$ \\
\hline benzaldeído & 969 & $4,5 \pm 0,8$ & $51(100), 77(97), 106(68), 105(66), 50(64), 52(24), 78(16)$ \\
\hline $\begin{array}{l}\text { 6-metil-5-hepten- } \\
\text { 2-ona }\end{array}$ & 980 & 0,8 -tr \pm nd & $43(100), 40(58) 41(56), 55(21), 69(13), 58(8), 108(8)$ \\
\hline NI & 988 & $3,2 \pm 0,3$ & $43(100), 67(72), 41(70), 55(54), 68(40), 53(14), 42(13)$ \\
\hline octanal & 1005 & $4,6 \pm 1,7$ & $43(100), 41(94), 44(70), 42(37), 55(35), 56(31), 57(28)$ \\
\hline NI & 1014 & $3,9 \pm 0,1$ & $43(100), 55(90), 41(82), 67(81), 68(47), 53(18), 40(17)$ \\
\hline fenilacetaldeído & 1056 & $18,5 \pm 1,4$ & $91(100), 65(36), 92(24), 51(17) 40(16), 63(14), 120(12)$ \\
\hline óxido cis de linalol & 1084 & tr \pm nd & $43(100), 59(60), 41(50), 55(31), 67(18), 68(16), 94(11)$ \\
\hline NI & 1110 & $4,8 \pm 0,0$ & $41(100), 43(74), 44(58), 57(54), 56(36), 42(29), 55(29)$ \\
\hline NI & 1116 & $9,1 \pm 1,0$ & $43(100), 41(63), 71(46), 55(31), 67(19), 82(19), 53(14)$ \\
\hline NI & 1153 & $11,2 \pm 2,5$ & $43(100), 55(77), 41(64), 67(20), 53(14), 71(14), 93(12)$ \\
\hline 2-isononenal & 1158 & $13,5 \pm 3,3$ & $43(100), 55(75), 41(66), 67(19), 71(18), 53(13), 93(12)$ \\
\hline NI & 1172 & $3,9 \pm 0,8$ & $43(100), 55(91), 41(79), 67(23), 71(19), 53(17), 40(17)$ \\
\hline NI & 1201 & $2,6 \pm 0,5$ & $41(100), 69(51), 137(47), 55(39), 43(32), 109(23), 67(21)$ \\
\hline NI & 1219 & $3,0 \pm 0,7$ & $41(100), 94(69), 79(54), 43(43), 55(42), 67(34), 44(28)$ \\
\hline 1-p-menten-9-al & 1225 & $2,7 \pm 0,5$ & $94(100), 79(95), 41(84), 67(35), 55(34), 53(29), 43(20)$ \\
\hline
\end{tabular}

${ }^{1}$ Média ou amplitude de 4 determinações (2 lotes em duplicata); ${ }^{2}$ d.p.: desvio padrão; NI: composto não identificado; $\mathrm{tr}=$ traços; nd= não determinado

O antranilato de metila foi relatado em méis cítricos e considerado importante para confirmar a qualidade deste tipo de mel [13, 31, 32]. Porém, este composto não foi identificado nas amostras de méis de laranja analisadas neste trabalho, assim como também não foi detectado nas amostras analisadas por OVERTON \& MANURA [25] e por BOUSETA, COLLINS \& DUFOUR [7]. Os compostos 6-metil-5-hepten-2-ona e 2-isononenal estão sendo rela- 
tados como constituintes de mel pela primeira vez, neste trabalho.

A comparação dos resultados permite concluir que o perfil de voláteis das amostras de mel de eucalipto ( $\mathrm{Ta}$ bela 1) é distinto do perfil de voláteis das amostras mel de laranja (Tabela 2). Assim, é possivel que o perfil de voláteis possa ser um elemento de identificação do mel em função de sua origem botânica para amostras recém colhidas de mel.

A manutenção de um mesmo perfil de compostos voláteis para méis de uma mesma origem floral já havia sido relatada por BICCHI, BELLIARDO \& FRATINNI [6], que observaram o mesmo perfil cromatográfico de compostos voláteis de méis da região do Piemonte em diferentes anos de colheita.

\section{2 - Análise sensorial}

\subsection{1 - Terminologia descritiva}

Os provadores geraram cinco descritores de aroma e sete de sabor, que estão relacionados na Tabela 3, enquanto as referências sugeridas para o treinamento estão apresentadas na Tabela 4.

TABELA 3. Definição dos descritores sensoriais para a caracterização do perfil de aroma e sabor de mel de eucalipto e laranja.

\begin{tabular}{ll}
\hline DESCRITOR & DEFINIÇÃo \\
\hline $\begin{array}{l}\text { AROMA } \\
\text { Característico }\end{array}$ & $\begin{array}{l}\text { próprio do mel, que lembra mel; o conjunto de notas que } \\
\text { sente-se ao abrir-se um vidro de mel. } \\
\text { calda de açúcar pouco cozido, o início da caramelização do } \\
\text { açúcar. }\end{array}$ \\
Adocicado & $\begin{array}{l}\text { que apresenta perfume de qualquer flor. } \\
\text { Floral } \\
\text { Ceranja/cítrico/rosa) }\end{array}$ \\
$\begin{array}{l}\text { Gueimado/Fumo } \\
\text { odor da cera alveolada, separada do favo. } \\
\text { referente à queimada de mata ou folhas secas e torradas } \\
\text { SABOR }\end{array}$ & $\begin{array}{l}\text { como fumo e mate. } \\
\text { Adocicado }\end{array}$ \\
Floral & $\begin{array}{l}\text { sabor muito doce com notas características de mel. } \\
\text { que apresente perfume de qualquer flor, sentido na boca } \\
\text { durante a degustação. } \\
\text { relativo ao sabor da cera alveolada (separada do favo). } \\
\text { relativo ao sabor de folha seca e torrada, como fumo ou } \\
\text { mate. }\end{array}$ \\
Ácido & $\begin{array}{l}\text { percepção do gosto ácido, conferida por ácidos orgânicos } \\
\text { o sabor que permanece na boca após a ingestão }\end{array}$ \\
Residual &
\end{tabular}

TABELA 4. Referências sugeridas para a definição dos atributos sensoriais.

\begin{tabular}{ll}
\hline REFERÊNCIA & ATRIBUTO \\
\hline cera alveolada & cera/favo \\
essência de laranja & floral - cítrico-laranja \\
rodela de limão & floral - cítrico limão \\
rosa vermelha aberta & floral - perfume \\
flor do campo & floral - flor \\
melado & adocicado \\
fumo de rolo picado & queimado - fumo \\
furfural diluído em água & queimado \\
folhas de eucalipto & queimado \\
\hline
\end{tabular}

\subsection{2 - Perfil de aroma e sabor das amostras}

A Figura 3 mostra o perfil de aroma e sabor das amostras de méis analisadas. A amostra de mel de laranja apresentou maior intensidade de aroma e sabor floral e de cera, enquanto as amostras de mel de eucalipto apresentaram maior intensidade de aroma e sabor queimado. Este fato pode ser confirmado através dos resultados da análise estatística (ANOVA e Tukey), os quais indicaram que as amostras de mel de laranja e de eucalipto diferiram significativamente $(p \leq 0,05)$ entre si em 9, dos 12 descritores analisados. A intensidade média de cada descritor, para cada amostra, é mostrada na Tabela 5.

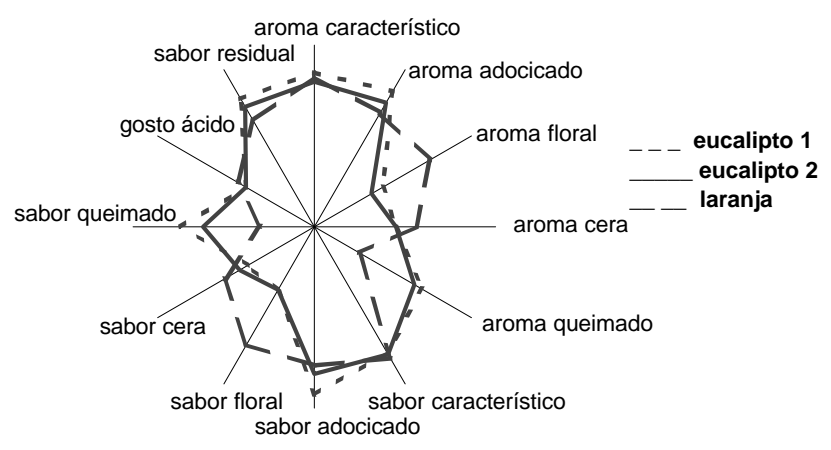

FIGURA 3. Perfil de aroma e sabor de amostras de mel de laranja e eucalipto.

TABELA 5. Médias da equipe sensorial para a intensidade dos atributos de aroma e sabor das amostras de méis

\begin{tabular}{lccc}
\hline \multirow{2}{*}{$\begin{array}{l}\text { Atributo } \\
\text { Sensorial }\end{array}$} & \multicolumn{3}{c}{ Amostras } \\
\cline { 2 - 4 } Aroma & Eucalipto1 & Eucalipto 2 & Laranja \\
Característico & $6,8^{\mathrm{a}}$ & $6,4^{\mathrm{a}}$ & $6,6^{\mathrm{a}}$ \\
Adocicado & $6,9^{\mathrm{a}}$ & $6,3^{\mathrm{a}}$ & $5,8^{\mathrm{b}}$ \\
Floral & $3,5^{\mathrm{b}}$ & $2,9^{\mathrm{b}}$ & $5,9^{\mathrm{a}}$ \\
Cera & $3,6^{\mathrm{b}}$ & $3,6^{\mathrm{b}}$ & $4,5^{\mathrm{a}}$ \\
Queimado & $5,5^{\mathrm{a}}$ & $5,1^{\mathrm{a}}$ & $2,3^{\mathrm{b}}$ \\
Sabor & & & \\
Característico & $6,4^{\mathrm{a}}$ & $6,5^{\mathrm{a}}$ & $6,7^{\mathrm{a}}$ \\
Adocicado & $7,4^{\mathrm{a}}$ & $6,5^{\mathrm{b}}$ & $6,1^{\mathrm{b}}$ \\
Floral & $3,2^{\mathrm{b}}$ & $3,2^{\mathrm{b}}$ & $6,0^{\mathrm{a}}$ \\
Cera & $3,4^{\mathrm{b}}$ & $3,8^{\mathrm{b}}$ & $4,6^{\mathrm{a}}$ \\
Queimado & $5,9^{\mathrm{a}}$ & $4,9^{\mathrm{b}}$ & $2,4^{\mathrm{c}}$ \\
Ácido & $3,5^{\mathrm{a}}$ & $3,5^{\mathrm{a}}$ & $3,9^{\mathrm{a}}$ \\
Residual & $6,5^{\mathrm{a}}$ & $6,1^{\mathrm{a}}$ & $5,4^{\mathrm{b}}$ \\
\hline
\end{tabular}

Médias com letras em comum numa mesma linha não diferem significativamente $(\mathrm{p} \leq 0,05)$ entre si.

A Tabela 5 mostra que as três amostras não apresentaram diferenças significativas $(\mathrm{p} \leq 0,05)$ entre si para os atributos aroma característico, sabor característico e gosto ácido. Em relação ao atributo sabor queimado verifica-se que as três amostras apresentaram diferença significativa $(\mathrm{p} \leq 0,05)$ entre $\mathrm{si}$, sendo que a amostra de mel de laranja apresentou a menor média. Em relação 
ao sabor adocicado, uma das amostras de mel de eucalipto e o mel de laranja não apresentaram diferença significativa ao nível de 5\%, mas diferiram da outra amostra de mel de eucalipto. Em relação aos demais atributos (aroma adocicado, aroma floral, aroma cera, aroma queimado, sabor floral, sabor cera e sabor residual) as amostras de mel de eucalipto não apresentaram diferença significativa entre si ao nível de 5\% mas diferiram da amostra de mel de laranja.

A análise multivariada dos dados sensoriais realizada através da Análise de Componentes Principais (ACP) foi efetuada empregando-se a média de cada atributo obtida pela equipe sensorial por amostra em cada repetição. Foram analisados os seguintes atributos: aroma cera, sabor cera, aroma floral, sabor floral, aroma queimado, sabor queimado e sabor residual.

Através da Análise de Componentes Principais (ACP), (Figura 4), verifica-se que os dois primeiros componentes (CP1 e CP2) responderam por 95\% da variação observada, sendo que o primeiro explicou $87 \%$ desta variação. Os descritores empregados discriminaram adequadamente as amostras analisadas.

$\mathrm{Na}$ ACP, os vetores representam os descritores utilizados e vetores que se situam próximos entre si, sugerem atributos que apresentam correlações estatisticamente significativas. Desta forma a Figura 4 sugere que os atributos aroma e sabor queimado estão bastante relacionados, o mesmo ocorrendo com os descritores aroma e sabor floral; aroma e sabor cera. O sabor residual parece apresentar relação com os atributos aroma e sabor queimado.

Ambas as amostras de mel de eucalipto apresentaram como nota mais marcante a dos descritores aroma e sabor queimado e sabor residual. A repetibilidade, avaliada pela distância entre os pontos referentes a uma mesma amostra, foi alta, visualizada quando projetada no eixo prin 1 , que responde por $67 \%$ da variabilidade. A amostra de mel de laranja caracterizou-se pelo seu aroma e sabor floral e aroma e sabor cera, estando bastante afastada das amostras de mel de eucalipto.

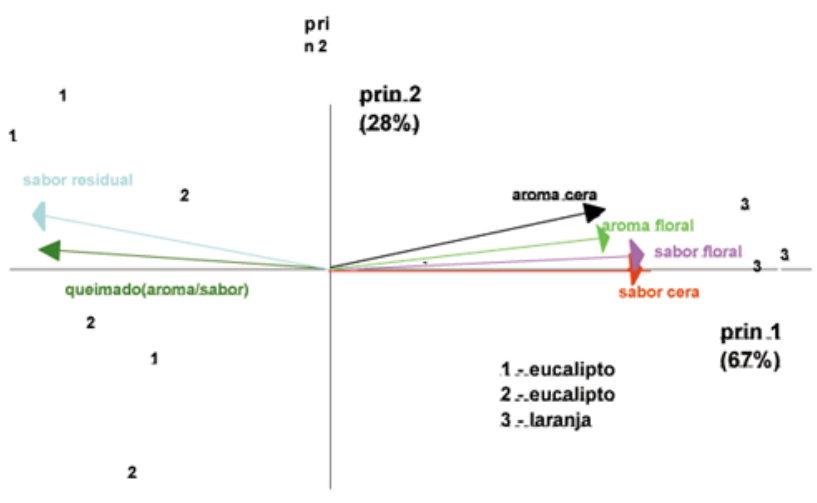

FIGURA 4. Análise dos Componentes Principais do aroma e sabor de méis de eucalipto e laranja.

\section{3 - Importância odorifera dos compostos voláteis de mel de eucalipto e de laranja}

O aroma dos compostos voláteis, eluídos da coluna cromatográfica, foram avaliados individualmente a fim de se verificar quais compostos apresentavam contribuição sensorial. Os resultados dessa avaliação, obtidos por "sniffing", das amostras de mel de eucalipto e de laranja, encontram-se nas Tabelas 6 e 7, respectivamente.

TABELA 6. Descrição sensorial dos compostos voláteis de mel de eucalipto obtida por "sniffing"

\begin{tabular}{|c|c|}
\hline $\begin{array}{l}\text { Composto ou } \\
\text { Índice de Kovats }\end{array}$ & Descrição \\
\hline 892 & adocicado, floral \\
\hline 915 & fedido, levedura, acre, verde, desagradável \\
\hline 928 & doce, laranja \\
\hline 958 & adstringente, ácido, gás, podre, desagradável \\
\hline 1000 & mato, boldo, amargo \\
\hline nonanal & eucalipto, verde, cítrico, quente e doce \\
\hline nonanol & queimado, remédio, mel, doce \\
\hline
\end{tabular}

Alguns descritores gerados neste trabalho para caracterizar os voláteis odoriferos presentes em mel de eucalipto foram similares aos obtidos por WOOTON, EDWARDS \& FARAJI-HAREMI [32] e GRADDON, MORRISSON \& SMITH [16], em pesquisa realizada com mel: tabaco, folhas queimadas, queimado, desagradável e mel.

O nonanal, descrito como eucalipto, verde, cítrico e doce, é descrito na literatura como possuindo características florais [5]. No entanto, em cera de abelhas [12] foi também descrito como forte, cítrico, doce.

TABELA 7. Descrição sensorial de compostos voláteis de mel de laranja obtida por "sniffing".

\begin{tabular}{ll}
\hline $\begin{array}{l}\text { Composto ou } \\
\text { Índice de Kovats }\end{array}$ \\
\hline benzaldeído & adocicado, cítrico, laranja \\
988 & laranja suave, flor \\
fenilacetaldeído & floral forte, doce, mel \\
1110 & flor, fumo, adocicado \\
1116 & flor, cítrico \\
1201 & baunilha, doce, levedura \\
$1-p-m e n t e n-9-a l$ & fedido, formol, quente, gás, amêndoa \\
\hline
\end{tabular}

O aroma do benzaldeído foi descrito como adocicado, cítrico e laranja, enquanto nos trabalhos de BAUER \& GARBE [5], foi descrito como amêndoa amarga. Fenilacetaldeído foi descrito neste estudo como floral forte, doce e mel e esse composto foi descrito como apresentando aroma de jacinto e lilás, em mel de "heather" 
(heather honeys). Fenilacetaldeído é empregado na formulação de aroma artificial de mel [21].

Visto que a percepção da qualidade sensorial de um composto pode variar em função de sua concentração e da sensibilidade do provador, a sua descrição pode diferir de um estudo para outro.

\section{4 - Relação entre o perfil de voláteis e o perfil de aroma e sabor da amostras.}

O perfil sensorial das amostras do mel de eucalipto revelou notas de aroma e sabor queimado, as quais podem estar relacionadas ao composto nonanol, uma vez que esse composto foi descrito na avaliação olfatométrica como queimado, remédio. $\mathrm{O}$ aroma característico do mel de eucalipto pode estar associado ao nonanal, descrito por "sniffing" como possuindo aroma de eucalipto.

O perfil de aroma e sabor do mel de laranja caracterizou-se pelos descritores floral e cera. Fenilacetaldeído e benzaldeído foram descritos como floral, doce e mel, e podem ser os voláteis associados ao aroma e sabor floral e de cera detectados pela equipe descritiva no mel de laranja. A importância dos compostos não identificados, com Índices de Kovats de 988, 1110 e 1116, ainda deve ser observada, pois apresentaram aroma cítrico ou floral.

\section{4 - CONCLUSÕES}

Os perfis de voláteis presentes em méis de eucalipto e laranja diferiram entre si, indicando que existe um perfil característico em função da origem botânica do mel recém-colhido.

O nonanal foi considerado positivamente identificado e é um dos compostos majoritários do mel de eucalipto recém-extraído do favo. Os compostos 2-heptanona, 2heptanol e 2-octanol também foram identificados por espectrometria de massas e índice de Kovats neste tipo de mel.

Benzaldeído e óxido cis de linalol, n-heptanal, 6metil-5-hepten-2-ona, octanal, fenilacetaldeído, 2isononenal e 1-p-menten-9-al foram positivamente identificados no mel de laranja recém-extraído do favo.

Existem diferenças sensoriais acentuadas entre os méis de eucalipto e laranja, conforme determinado por uma equipe de provadores treinados.

O mel de eucalipto foi caracterizado sensorialmente pelos atributos aroma e sabor de queimado, que estão relacionados com a descrição olfatométrica do composto nonanol, enquanto o nonanal que foi descrito como eucalipto, foi considerado importante para o aroma e sabor de mel de eucalipto.

O mel de laranja foi caracterizado pelos atributos aroma e sabor de cera e floral, que estão relacionados com a descrição olfatométrica do composto fenilacetaldeído, enquanto o benzaldeído que foi descrito como adocicado, laranja, foi considerado importante para o aroma e sabor de mel de laranja.

\section{5 - REFERÊNCIAS BIBLIOGRÁFICAS}

[1] ACREE, T.E.; BARNARD, J. \& CUNNINGHAM, D.G. A procedure for the sensory analysis of gas chromatographic effluents. Food Chem., v. 24, p. 273286, 1984.

[2] ACREE, T.E.; BARNARD, J. \& CUNNINGHAM, D.G. Gas chromatography-olfactometry and Charm Analysis. In: MAARSE AND VAN DER HEIJ,D.G. (Ed) Trends in flavor research. Oxford: Elsevier Science Publishers, 1994.

[3] BARTH,O. M. Pollen in monofloral honeys from Brazil. J. Apic. Res., v. 29, n. 2, p. 89-94, 1990.

[4] BASTOS, D.H.M.; DA SILVA, M.A.A.P.; FRANCO, M.R.B. Optimization of the isolation procedure of honey volatile compounds for further gas chromatography analysis. Alimentos e Nutrição, v. 9, p. 77-88, 1998.

[5] BAUER, K. \& GARBE, D. Common fragrance and flavor material: preparation, properties and uses. Weihein: VHC, 1985.

[6] BICCHI, C.,BELLIARDO, F. \& FRATTINI, C. Identification of the volatile components of some piemontese honeys. J.Apic.Res., v. 22, n. 2, p. 130-136, 1983.

[7] BOUSETA, A., COLLINS, S. \& DUFOUR, J.P. Characteristic aroma profiles of unifloral honeys obtained with a dynamic Headspace CG-MS system. J. Apic. Res., n. 31, v. 2, p. 96-109, 1992.

[8] BOUSETA, A.; SCHEIRMAN, V. \& COLLIN, S. Flavor and free amino acid composition of lavander and eucalyptus honeys. J. Food Sci., v. 61, n. 4, p. 683-687, 1996.

[9] CHERCHI, A; SPANNEDA, L. \& TUBEROSO, C.I.G. Influence of aging on the quality of honey. Industria Conservi. v.78, p. 266-271, 1997.

[10] CONTE, L.S.; MIORINI, M.; GIOMO, A.;BERTACCO, G.; ZIRONI, R. Evaluation of some fixed components for unifloral honey characterization. J. Agric. Food. Chem., v. 46, p. 1844-1849, 1998.

[11] D'ARCY, B.R.; RINTOUL, G.B.; ROWLATR, C.Y.; BLACKMAN, A.J. Composition of australian honey extractives. Norisoprenoids, monoterpenes, and other natural volatiles from blue gum (Eucalyptus leucoxylon) and yellow box (Eucalyptus mellidora) honeys. J. Agric. Food Chem., v. 45, p. 1834-1843, 1997.

[12] FERBER, C.E.M \& NURSTEN, H.E. - The aroma of beeswax. J. Sci. Food Agric., v. 28, p. 311-318, 1977.

[13] FERRERES, F. GINER, J.M.\& TOMÁS-BARBERÁN, A. A comparative study of hesperetin and methyl anthranilate as markers of the floral origin of citrus honey. J. Sci. Food Agric., v. 65, p. 371-372, 1994.

[14] FERRERES, F.; ATRRADE, P.; GIL, M.I.; TOMÁSBARBERAAN, F.A. Floral nectar phenolics as biochemical markers for the botanical origin of heather honey. $\mathbf{z}$. Lebesm.Unters.Forsch., v. 202, p. 40-44, 1996.

[15] FRANCO. M.R. \& RODRIGUES-AMAYA, D.B. Trapping of sousop (annona muricata) juice volatiles on Porapak $Q$ by sucction. J. Sci. Food. Agric., v. 34, n. 3, p. 293299, 1983.

[16] GRADDON, A.D., MORRISON, J.D. \& SMITH, J.F. Volatile constituents of some unifloral australian honeys. J.Agric.Food Chem., v. 27, n. 4, p. 832-837, 1979.

[17] GUYOT, C.; BOUSETA, A.; SCHEIRMAN, V.; COLLIN, S. Floral origin markers of chesnut and lime tree honeys. J. Agric. Food Chem., v. 46, p. 625-633, 1998.

[18] GUYOT, C.; SCHEIRMAN, V.; COLLIN, S. Floral origin markers of heather honeys: Calluna vulgaris and Erica arborea. Food Chem., v. 64, p. 3-11, 1999. 
[19] JIMÉNEZ.M.; MATEO,J.J.; HUERTA,T.; MATEO,R. Influence of the storage conditions on some physicochemical and mycological parameters of honey. J. Sci. Food Agric., v. 64, p. 67-74, 1994.

[20] LOW, N. H.; SCHWEGER, C. \& SPORNS, P. Precautions in the use of melissopalinology. J. Apic. Res., v. 28, n. 1, p. 50-54, 1989.

[21] MAGA, J.A. Honey flavor. Lebesm. Wiss.u.Technol., v. 16, p. 65-68, 1983.

[22] MATEO, R.\& BOSCH-REIG, F. Classification of Spanish unifloral honeys by discriminant analysis of electrical conductivity, color, water content, sugars and $\mathrm{pH}$. J. Agric. Food Chem., v. 46, p. 393-400, 1998.

[23] MEIllard, M.; CIVILle, G.V.; CARR, B.T. Sensory evaluation techniques. CRC press: Boca Raton, Fl, 1987; v.2

[24] MOSKOWITZ, H.R. Product testing and sensorial evaluation of foods: marketing and $R \& D$ approaches. Wetport: Food and Nutrition Press, 1983.

[25] OVERTON, S.V. \& MANURA, J.J. Flavor and aroma in commercial bee honey- a purge and trap thermal desorption tecnique for identification and quantification of volatiles and semivolatiles in honey. Am. Lab., April, p. $45-53,1994$.

[26] POWERS, J.J. Techniques of analysis of flavors - Integration of sensory and instrumental methods. In: MORTON, I.D. \& MACLEOD, A. J. (Org.) Food Flavor. Developments in Food Science - 3A. Oxford: Elsevier Science Publishing, 1982. Cap. 2.

[27] SANCHO, M.T., MUNIATEGUI, S., HUIDOBRO, J.F.,SIMALLOZANO, J. Provincial classification of Basque Country (northen Spain) honeys by their chemical composition. J. Apic. Res., v. 30, n. 3/4, p. 168-172, 1991.

[28] STONE, H.; SIDEL, J.; OLIVER, S.; WOOLSEY, A.; SINGLETON, R.C. Sensory evaluation by quantitative descriptive analysis. Food technology, v. 28, n. 11, p. 24-34, 1974.

[29] THOMAZINI, M., FRANCO, M.R.B. Metodologia para Análise dos Constituintes Voláteis do Sabor. Bol. SBCTA, v. 34 , n. 1, p. 52-59, 2000

[30] VISSER, F.R., ALLEN, J.M. \& SHAW, G.J. The effect of heat on the volatile flavor fraction from a unifloral honey. J.Apic.Res., v. 27, n. 3, p. 175-181, 1988

[31] WHITE, J.W. \& BRYANT JR., V. M. Assessing citrus honey quality: pollen and methyl anthranilate content. J. Agric. Food Chem. v.44, p. 3423-3425, 1996.

[32] WOOTON, M., EDWARDS, R.A. \& FARAJI-HAREMI Effect of accelerated storage conditions on the chemical composition and properties of Australian Honeys. III Changes in volatile compounds. J.Apic.Res., v. 17, n. 3, p. $167-172,1978$

\section{6 - AGRADECIMENTOS}

Os autores agradecem à FAPESP pelo auxílio financeiro a esta pesquisa (processo no 94/2548-0) e à CAPES pela bolsa concedida a um dos autores. À Tereza Cristina Gianini e demais membros do Laboratório de Abelhas das USP pela análise polínica e aos apiários Api Vita (Rio Claro), Flor de Liz (Campo Limpo) e Boza (Araras) pelas amostras de mel. 